\title{
Commentary: Transient Postural Vestibulo-Cerebellar Syndrome in Three Dogs With Presumed Cerebellar Hypoplasia
}

\author{
Shinji Tamura* \\ Tamura Animal Clinic, Hiroshima, Japan \\ Keywords: positioning head tilt, dog, cerebellar, nodules, ventral uvula
}

\begin{abstract}
A Commentary on
Transient Postural Vestibulo-Cerebellar Syndrome in Three Dogs With Presumed Cerebellar Hypoplasia

by Prikryl, M., Caine, A., and Palus, V. (2020). Front. Vet. Sci. 7:453. doi: 10.3389/fvets.2020.00453
\end{abstract}

\section{INTRODUCTION}

OPEN ACCESS

Edited by:

Adalberto Merighi,

University of Turin, Italy

Reviewed by:

Giacomo Rossi,

University of Camerino, Italy

Simon Platt,

University of Georgia, United States

*Correspondence:

Shinji Tamura

cqx03426@ms8.megaegg.ne.jp

Specialty section:

This article was submitted to

Veterinary Neurology and

Neurosurgery,

a section of the journal

Frontiers in Veterinary Science

Received: 02 October 2020

Accepted: 27 January 2021

Published: 19 February 2021

Citation:

Tamura S (2021) Commentary:

Transient Postural

Vestibulo-Cerebellar Syndrome in Three Dogs With Presumed Cerebellar Hypoplasia. Front. Vet. Sci. 8:613521.

doi: 10.3389/fvets.2021.613521
The use of the technical term "positioning head tilt" in a recently published article entitled "Transient Postural Vestibulo-Cerebellar Syndrome in Three Dogs with Presumed Cerebellar Hypoplasia" by Prikryl et al. seems incorrect. The authors appear to have overlooked a slight head tilt in the Case 1 movie. The correct meaning of positioning head tilt is discussed in this general commentary article.

\section{WHAT IS "POSITIONING HEAD TILT?”}

Positioning head tilt is a neurological sign originally described in 2016 in three dogs with presumptive cerebellar nodulus and ventral uvula hypoplasia. Dogs with positioning head tilt can turn freely in any direction. The head is in a level position when static or when the dog walks in a straight line. However, the head tilts to the opposite side when the dog turns its head (1). The cerebellum maintains the position of the head unconsciously. Signaling by the vestibular system is inputted into the vestibulocerebellum (the vermis, the fastigial nucleus, and the flocculi) upon detection of head movement. The actual head position is detected by proprioceptive receptors (muscle spindles) within the oblique and rectus capitis muscles. The signal is inputted into the spinocerebellum (the paravermian cortex and the interposed nucleus) through the spinocuneocerebellar tract (2-8). 'Vestibular nuclear projections to the spinal cord are situated in the vestibulospinal tracts. The fibers terminate on interneurons that facilitate ipsilateral flexors and decussate to inhibit contralateral extensor muscle activity. The vestibulospinal tracts facilitate spinal reflexes, especially those involved in maintaining posture and the antigravity/extensor muscles. Turning the head to the left causes a shift in the distribution of body mass to the left. This shift in mass is supported by increased extension on the left side, which is reflexively induced by both myotatic and vestibular reflexes. This also reduces extension on the right side, and thereby minimizes weight transfer to the left' (1). The cerebellar nodulus and ventral uvula (NU) coordinates this system by inhibition of stimulation of vestibular nuclei in order to maintain a level head position in response to head movement (1). This inhibition is absent in animals with NU dysfunction, and positioning head tilt occurs. 


\section{DISCUSSION}

Positioning head tilt is not a vestibular deficit related to posture, as explained in the Introduction. Rather, it describes a vestibular deficit related to head movement (in other words, "postural changing"). The previously reported observation is not "positional head tilt," as mentioned in the third paragraph of the Discussion section, but "positioning head tilt" (1). "Positional" is related to posture and "positioning" to postural changes. They have completely different meanings like "positional nystagmus" and "positioning nystagmus" in human medicine (9). Since various vestibular signs elicited by the postural changes of the head are discussed in the original article, for the same reason, "positioning vestibularcerebellar syndrome" is a more accurate description of the condition than the "postural vestibular-cerebellar syndrome" in the title.

\section{REFERENCES}

1. Tamura S, Nakamoto Y, Uemura T, Tamura Y. Head tilting elicited by head turning in three dogs with hypoplastic cerebellar nodulus and ventral uvula. Front Vet Sci. (2016) 3:104. doi: 10.3389/fvets.2016.00104

2. Sanders SG. Cerebellar diseases and tremor syndromes. In: Dewey CW, DaCosta RC, editors. Practical Guide to Canine and Feline Neurology. 3rd ed. Ames, IA: Wiley Blackwell (2016). p. 299-327.

3. De Lahunta A, Glass E, Kent M. editors. Cerebellum. In: Veterinary Neuroanatomy and Clinical Neurology. 4th ed. St. Louis, MO: Elsevier (2015). p. 368-408.

4. Uemura EE. Cerebellum. editors. In: Fundamentals of Canine Neuroanatomy and Neurophysiology. Ames, IA: Wiley Blackwell (2015). p. 288-306.

5. Thomson C, Hahn C. editors. The cerebellum. In: Veterinary Neuroanatomy: A Clinical Approach. St. Louis, MO: Elsevier (2012). p. 67-74.

6. Thomson C, Hahn C. editors. Vestibular system. In: Veterinary Neuroanatomy: A Clinical Approach. St. Louis, MO: Elsevier (2012). p. 75-83.
Positioning head tilt was observed especially in the first half of the Case 1 supplemental movie (https://www.frontiersin.org/ articles/10.3389/fvets.2020.00453/full\#supplementary-material); however, the authors did not observe it. Positioning head tilt can be easily overlooked, especially in animals with only mild tilting. Long-time observation of free walking is necessary to evaluate positioning head tilt.

\section{AUTHOR CONTRIBUTIONS}

The author confirms being the sole contributor of this work and has approved it for publication.

\section{ACKNOWLEDGMENTS}

We would like to thank Editage (www.editage.com) for English language editing.

7. Thomson C, Hahn C. editors. Reflexes and motor systems. In: Veterinary Neuroanatomy: A Clinical Approach. St. Louis, MO: Elsevier (2012). p. 47-57.

8. Apps R, Hawkes R, Aoki S, Bengtsson F, Brown A, Chen G, et al. Cerebellar modules and their role as operational cerebellar processing units: a consensus paper. Cerebellum. (2018) 17:654-82. doi: 10.1007/s12311-018-0952-3

9. Brandt T. Positional and positioning vertigo and nystagmus. J Neurolo Sci. (1990) 95:3-28.

Conflict of Interest: The author declares that the research was conducted in the absence of any commercial or financial relationships that could be construed as a potential conflict of interest.

Copyright (c) 2021 Tamura. This is an open-access article distributed under the terms of the Creative Commons Attribution License (CC BY). The use, distribution or reproduction in other forums is permitted, provided the original author(s) and the copyright owner(s) are credited and that the original publication in this journal is cited, in accordance with accepted academic practice. No use, distribution or reproduction is permitted which does not comply with these terms. 